БРЕДУН Е. В., БАЛАНЁВ Д. Ю., ВАУЛИНА Т. А., КРАСНОРЯДЦЕВА О. М., ЩЕГЛОВА Э. А.

ТЕМПОРАЛЬНЫЕ ОСОБЕННОСТИ СТУДЕНТОВ КАК КОГНИТИВНЫЕ ДИАГНОСТИЧЕСКИЕ ХАРАКТЕРИСТИКИ...

РоссиЙский психологИЧЕСКИй ЖУРнАл, 2020, Т. 17, № 1, 60-73. doi: 10.21702/rpj.2020.1.5

ПЕДАГОГИЧЕСКАЯ ПСИХОЛОГИЯ

УДК 159.9.072.43 doi: 10.21702/rpj.2020.1.5

Оригинальная научная статья

\title{
Темпоральные особенности студентов как когнитивные диагностические характеристики: контекст адаптивного образования
}

\author{
Екатерина В. Бредун, Дмитрий Ю. Баланёв, Татьяна А. Ваулина, Ольга М. Краснорядцева*, \\ Элеонора А. Щеглова \\ Национальный исследовательский Томский государственный университет, г. Томск, Российская \\ Федерация \\ *E-mail: krasnoo@mail.ru \\ ORCID ID: https://orcid.org/0000-0003-4214-8065, https://orcid.org/0000-0001-9461-7973, \\ https://orcid.org/0000-0002-3837-3756, https://orcid.org/0000-0003-1549-9994, \\ https://orcid.org/0000-0003-3360-038X
}

\begin{abstract}
Аннотация
Ввеление. В статье представлены результаты эКспериментального исслеАования инАивиАуального темпорального своеобразия процесса организации стуАентом когнитивного пространства в процессе решения залач.

Метолы. Кратко описан метолический инструментарий, вкАючающий в себя как тралиционные тестовые опросники Аля выявления темпоральных особенностей субъективного восприятия времени («Семантический Аифореренциал времени», «Временная перспектива»); так и модифицированные и авторские исследовательские приемы Аля выявления темпоральных особенностей когнитивной Аеятельности испытуемых при решении пространственных заАач в условиях ^абораторного эксперимента («Ментальное вращение», «Точность»).

Результаты. В условиях ^абораторного эксперимента получены новые исслеАовательские Аанные о темпоральной специфике конструирования стуАентом Своего инАивиАуального когнитивного пространства. Использование процеАур прогностического моделирования позволи^о зафриксировать наличие структурных связей межАу восприятием времени, когнитивными особенностями решения залач и разной стабильностью акалемической успеваемости. Экспериментально Аоказано, что в качестве темпоральных предикторов уровня акалемических Аостижений в стуленческом возрасте выступают специфика скорости и результативности выполнения когнитивных залач на точность и когнитивных заАач на ментальное вращение.

ОбсужАение результатов. Описан исслеАОвательский оракт: у стуАентов с АОминирующей временной ориентацией на настоящее и отличающихся тем, что они постоянно ищут новые стимулы и ощущения в актуальном времени, наблюАаются Аостаточно выраженные Аефиициты в выборе образовательных стратегий на основе более Аолгосрочных и четких целей на будущее. В качестве важного аспекта в персонализации обучения обозначено, что студент сам Аолжен понимать, какие временные, когнитивные и иные особенности переработки инорормации он имеет, чтобы самостоятельно организовывать свою образовательную среду. ОбсужАаются возможности использования когнитивных Аиагностических характеристик при прогнозировании и оперативной коррекции инАивиАуаАьной траектории образовательного пути студента в рамках аАаптивного поАхода в образовании.
\end{abstract}


БРЕДУН Е. В., БАЛАНЁВ Д. Ю., ВАУЛИНА Т. А., КРАСНОРЯДЦЕВА О. М., ЩЕГЛОВА Э. А.

ТЕМПОРАЛЬНЫЕ ОСОБЕННОСТИ СТУДЕНТОВ КАК КОГНИТИВНЫЕ ДИАГНОСТИЧЕСКИЕ ХАРАКТЕРИСТИКИ...

РосСИЙСКИЙ пСИХОЛОГИЧЕСКИЙ ЖУРнАл, 2020, Т. 17, № 1, 60-73. doi: 10.21702/rpj.2020.1.5

ПЕДАГОГИЧЕСКАЯ ПСИХОЛОГИЯ

\section{КАючевые слова}

темпоральность, предиктор, субъективное восприятие, восприятие времени, акалемическая успешность, временная перспектива, когнитивные залачи, ментальное вращение, скорость, когнитивные стратегии

\section{Основные положения}

$\checkmark$ инАивиАуальное темпоральное своеобразие процесса организации студентом когнитивного пространства (специфика скорости и результативности выполнения когнитивных заАач) выступает в качестве когнитивной Аиагностической характеристики соответствия временному пространству когнитивной среды и тем требованиям, которые она преАьявляет;

> стуленты, имеющие разные типологические особенности Аоминирующей временной ориентации и выбора когнитивных стратегий в ситуации реального решения пространственных залач, отличаются выраженной моАальностью стабильности акалемической успешности; $\checkmark$ темпоральные различия у субъектов образовательного процесса могут рассматриваться как значимое основание необходимости разнообразия вариантов темпоральности образовательных технологий, особенно в условиях нарастающей цифровизации современного образования.

\section{Для цитирования}

Бредун, Е. В., Баланёв, Д. Ю., Ваулина, Т. А., Краснорядцева, О. М. и Щеглова, Э. А. (2020). Темпоральные особенности студентов как когнитивные диагностические характеристики: контекст адаптивного образования. Российский психологический журнал, 17(1), 60-73. doi: 10.21702/rpj.2020.1.5

Дата получения рукописи: 07.02.2020

Дата окончания рецензирования: 05.03.2020

Дата принятия к публикации: 10.03.2020

\section{Введение}

Эффективное внедрение инновационных образовательных технологий в современном вузе предполагает, по мнению многих экспертов, в числе гибких изменений в организации образовательного процесса построение индивидуальных траекторий профессиональной подготовки студентов. В значительной степени эффективность обучения современного студента зависит от развитости таких метапрофессиональных компетенций, как готовность и способность к самоорганизации собственной деятельности, умение выбрать оптимальные когнитивные стратегии в поисково-исследовательской образовательной и научной деятельности. Сегодня становится понятным, что при разработке моделей индивидуальных образовательных траекторий нельзя обойти вниманием такие когнитивные характеристики человека, как темпоральные особенности, отражающие своеобразие временной структуры и хронотопической направленности жизни человека (Бредун, Краснорядцева и Щеглова, 2018). В научной литературе содержится достаточное количество сведений о психологической природе феномена субъективного восприятия времени, начиная с первого употребления термина «временная перспектива» Л. Франком (Frank, 1939). Авторы статьи не ставят своей задачей представить скрупулезный трансспективный анализ становления представлений в психологической науке о данном феномене. Отметим, однако, тех исследователей, работы которых позволили авторам статьи 
БРЕДУН Е. В., БАЛАНЁВ Д. Ю., ВАУЛИНА Т. А., КРАСНОРЯДЦЕВА О. М., ЩЕГЛОВА Э. А.

ТЕМПОРАЛЬНЫЕ ОСОБЕННОСТИ СТУДЕНТОВ КАК КОГНИТИВНЫЕ ДИАГНОСТИЧЕСКИЕ ХАРАКТЕРИСТИКИ...

РоссиЙскиЙ психологИЧЕСКИЙ жУРнАл, 2020, Т. 17, № 1, 60-73. doi: 10.21702/rpj.2020.1.5

ПЕДАГОГИЧЕСКАЯ ПСИХОЛОГИЯ

определить свой исследовательский фокус относительно понимания структуры временной ориентации. Это, конечно, ставшие уже классическими исследования P. G. Zimbardo, выделившего феномен перспективы как конструкта личности человека в зависимости от отношения ко времени (Зимбардо и Бойд, 2010; Zimbardo \& Boyd, 1999). Чрезвычайно интересный материал содержится в современных исследованиях, в рамках которых:

- выявлена взаимосвязь точности временных решений и способности синхронизации внутреннего ритма с ритмом, который предлагает окружающая среда (Grondin, 2010; Wearden, 2003; Wittmann, Dinich, Merrow, \& Roenneberg, 2006);

- установлены особенности взаимосвязи субъективного времени с восприятием, вниманием и памятью (Matthews \& Meck, 2016);

- определены возрастные и индивидуальные различия в различных проявлениях темпоральности (Droit-Volet, Wearden, \& Zélanti, 2015; van Heerden, 2016).

Особое внимание авторов статьи было обращено на работы исследователей, в которых рассматриваются различные аспекты влияния социального времени на жизнедеятельность человека (Thomas, Didierjean, Maquestiaux, \& Goujon, 2018; Arstila \& Lloyd, 2014; Болотова, 2006; Горобец, 2011; Горькая, 2014; Хмелевская, 2012).

Таким образом, проведенный анализ современного состояния и перспективных направлений изучения темпоральных характеристик жизненного мира человека позволил поставить исследовательскую задачу выявления возможных темпоральных предикторов уровня академических достижений в студенческом возрасте. Именно в юношеском возрасте временная перспектива тесно связана с реальными и образовательными достижениями обучающегося, поскольку включает в себя профессиональное самоопределение, будущие достижения, постановку образовательных и профессиональных целей, задач. Кроме того, для нас особое значение имели исследовательские данные, полученные Н. Д. Гордеевой о том, что в ходе решения когнитивной задачи настройка испытуемых на скорость выполнения, а не на точность, приводит к тому, что когнитивные процессы начинают притормаживаться (Гордеева, 1995). Это дало основание для еще одной исследовательской гипотезы, результаты проверки которой представлены в данной статье: о выделении в качестве темпорального предиктора академической успешности скорости решения когнитивных задач.

\section{Методы}

Для выявления темпоральных особенностей субъективного восприятия времени были использованы методики «Семантический дифференциал времени» (Вассерман, Трифонова и Червинская, 2009), и тест «Временная перспектива» (Zimbardo Time Perspective Inventory ZPTI) Ф. Зимбардо (Зимбардо и Бойд, 2010). Выбор методик обусловлен тем, что они позволяют изучить познавательные, эмоциональные компоненты времени и длительность переживаемых субъективных явлений времени (Zimbardo \& Boyd, 1999).

Для выявления темпоральных особенностей когнитивной деятельности испытуемых при решении пространственных задач была использована методика «Ментальное вращение» Р. Н. Шепарда и Дж. Мецлера (Cooper \& Shepard, 1973; Shepard \& Metzler, 1971) в модификации Д. Ю. Баланева (Клочко, Краснорядцева и Баланев, 2016). Данный вариант методики открывает возможности отображения перцептивного пространства не на плоскость, а в трехмерном пространстве за счет использования технологии 3D моделирования, что дает возможность конструирования мысленного движения как движения, производимого в пространстве. Цель 
БРЕДУН Е. В., БАЛАНЁВ Д. Ю., ВАУЛИНА Т. А., КРАСНОРЯДЦЕВА О. М., ЩЕГЛОВА Э. А.

ТЕМПОРАЛЬНЫЕ ОСОБЕННОСТИ СТУДЕНТОВ КАК КОГНИТИВНЫЕ ДИАГНОСТИЧЕСКИЕ ХАРАКТЕРИСТИКИ...

РосСИЙСКИЙ пСИХОЛОГИЧЕСКИЙ ЖУРнАл, 2020, Т. 17, № 1, 60-73. doi: 10.21702/rpj.2020.1.5

ПЕДАГОГИЧЕСКАЯ ПСИХОЛОГИЯ

данного методического приема состоит в измерении пространственно-временных характеристик самого процесса решения когнитивной задачи.

Экспериментальная процедура исследования состоит в последовательном представлении на экране стимульного материала из пары объектов. В каждой паре стимулов один из объектов повернут относительно другого; испытуемый должен принять решение об идентичности объектов-стимулов и при помощи графического пера выбрать один из двух ответов: «разные», «одинаковые». Всего каждому участнику предъявляется 96 задач ментального вращения.

Методика «Точность» (Клочко и др., 2016) является экспериментальной процедурой выявления отношений между скоростью и точностью решения диагностической задачи. Цель процедуры состоит в измерении пространственных и временных характеристик процессуально-когнитивной деятельности человека.

Процедура состоит из последовательного предъявления стимула в виде эллипсов с различным положением в пространстве экрана, разным диаметром, разным положением центра. Инструкция для испытуемых заключается в том, чтобы как можно точнее указать центр фигуры-стимула на экране при помощи пера. Время экспериментальной процедуры составляет 20 минут.

Показателем академической успеваемости выступил показатель среднего арифметического балльных оценок по дисциплинам, освоенным студентами-бакалаврами в течение не менее 3-х лет обучения (средний балл).

Экспериментальную группу составили 150 студентов Томского государственного университета, обучающихся на факультете исторических и политических наук, в институте прикладной математики и компьютерных наук, биологическом институте.

\section{Результаты}

Основываясь на эмпирических данных и используя процедуры прогностического моделирования, мы выдвинули гипотезу о структурных связях между восприятием времени, когнитивными особенностями решения задач и академической успеваемостью.

Для построения прогностической модели, описывающей влияние особенностей восприятия времени на успешность обучения в вузе, был проведен множественный регрессионный анализ. В качестве зависимой переменной выступал средний балл успеваемости студентов, который рассчитывался как среднее арифметическое отметок, полученных студентами за экзамены в период их обучения в вузе. В качестве независимых переменных были выбраны показатели, измеряемые методиками «Семантический дифференциал времени» и «Временная перспектива» ( $\mathrm{N}=20)$. Алгоритм включения независимых переменных в уравнение регрессии осуществлялся с помощью пошагового метода «исключение». В результате была получена регрессионная модель ( $p=0,003)$, в которую вошли 8 предикторов (табл. 1, 2, 3). Согласно полученной модели, 44 \% дисперсии переменной «средний балл» обусловлено влиянием таких предикторов, как «будущее», «ощущаемость прошлого времени», «активность настоящего времени», «структура настоящего времени», «ощущаемость настоящего времени», «эмоции будущего времени», «величина будущего времени» и «ощущаемость будущего времени». Коэффициенты регрессии (табл. 3) показывают, что предикторы «будущее», «величина будущего времени», «структура настоящего времени», «ощущаемость настоящего времени» положительно коррелируют с зависимой переменной «средний балл», в то время как «ощущаемость прошлого времени», «активность настоящего времени», «эмоции будущего времени» и «ощущаемость будущего времени»- отрицательно. 
БРЕДУН Е. В., БАЛАНЁВ Д. Ю., ВАУЛИНА Т. А., КРАСНОРЯДЦЕВА О. М., ЩЕГЛОВА Э. А.

ТЕМПОРАЛЬНЫЕ ОСОБЕННОСТИ СТУДЕНТОВ КАК КОГНИТИВНЫЕ ДИАГНОСТИЧЕСКИЕ ХАРАКТЕРИСТИКИ...

РосСИйский психологИЧЕСКИй жУРнАл, 2020, Т. 17, № 1, 60-73. doi: 10.21702/rpj.2020.1.5

ПЕДАГОГИЧЕСКАЯ ПСИХОЛОГИЯ

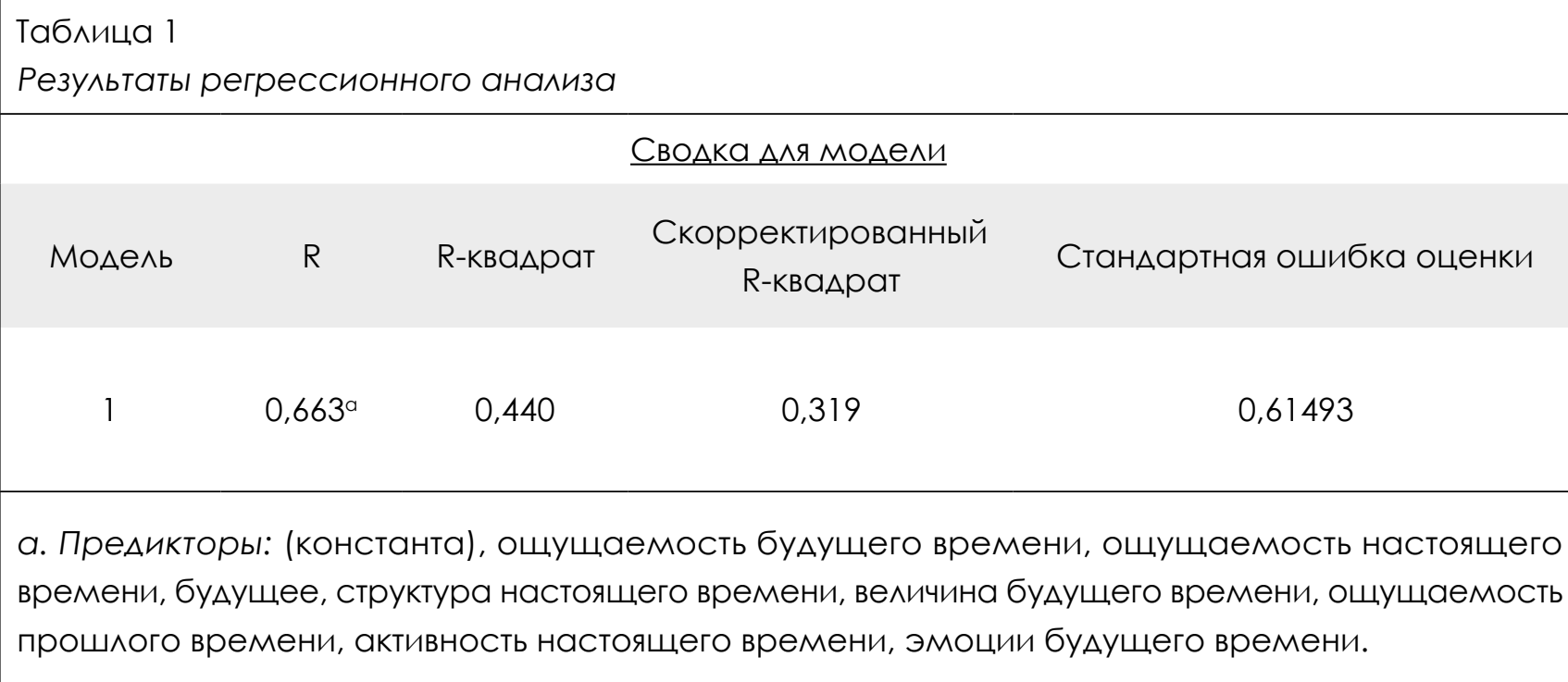

\begin{tabular}{|c|c|c|c|c|c|}
\hline \multicolumn{6}{|c|}{$\begin{array}{l}\text { Таблица } 2 \\
\text { Результаты регрессионного анализа }\end{array}$} \\
\hline \multicolumn{6}{|c|}{$\underline{A N O V A}^{a}$} \\
\hline Mose^b & $\begin{array}{l}\text { Сумма } \\
\text { кванратов }\end{array}$ & Ст. св. & $\begin{array}{l}\text { Средний } \\
\text { квалрат }\end{array}$ & $\mathrm{F}$ & Значимость \\
\hline \multirow[t]{2}{*}{ Регрессия } & 10,997 & 8 & 1,375 & \multirow[t]{3}{*}{3,635} & \multirow[t]{3}{*}{$0,003^{b}$} \\
\hline & 13,991 & 37 & \multirow[t]{2}{*}{0,378} & & \\
\hline Всего & 24,988 & 45 & & & \\
\hline \multicolumn{6}{|c|}{ а. Зависимая переменная: срелний бал^; } \\
\hline \multirow{2}{*}{\multicolumn{6}{|c|}{$\begin{array}{l}\text { b. Предикторы: (константа), ощущаемость будущего времени, ощущаемость настоящего } \\
\text { времени, будущее, структура настоящего времени, величина будущего времени, ощущаемость }\end{array}$}} \\
\hline & & & & & \\
\hline \multicolumn{6}{|c|}{ прошлого времени, активность настоящего времени, эмоции будущего времени. } \\
\hline
\end{tabular}


БРЕДУН Е. В., БАЛАНЁВ Д. Ю., ВАУЛИНА Т. А., КРАСНОРЯДЦЕВА О. М., ЩЕГЛОВА Э. А.

ТЕМПОРАЛЬНЫЕ ОСОБЕННОСТИ СТУДЕНТОВ КАК КОГНИТИВНЫЕ ДИАГНОСТИЧЕСКИЕ ХАРАКТЕРИСТИКИ...

РОССИЙСКИЙ ПСИХОЛОГИЧЕСКИЙ ЖКУРнАЛ, 2020, Т. 17, № 1, 60-73. doi: 10.21702/rpj.2020.1.5

ПЕДАГОГИЧЕСКАЯ ПСИХОЛОГИЯ

Таблица 3
Результаты регрессионного анализа

$\underline{\text { Коэррорициенты }}^{a}$

\begin{tabular}{|c|c|c|c|c|c|}
\hline \multicolumn{6}{|c|}{$\underline{\text { Коэордрициенты }}^{a}$} \\
\hline \multirow{2}{*}{ Mо $\triangle \mathrm{e} \wedge \mathrm{b}$} & \multicolumn{2}{|c|}{$\begin{array}{c}\text { Нестандартизованные } \\
\text { коэорорициенты }\end{array}$} & \multirow[t]{2}{*}{$\begin{array}{c}\text { Стандартизованные } \\
\text { коэфофициенты }\end{array}$} & \multirow{2}{*}{$\mathrm{T}$} & \multirow{2}{*}{ Значимость } \\
\hline & B & $\begin{array}{c}\text { Стандартная } \\
\text { ошибка }\end{array}$ & & & \\
\hline (Константа) & 3,802 & 0,889 & & 4,278 & 0,000 \\
\hline Будущее & 0,507 & 0,208 & 0,330 & 2,438 & 0,020 \\
\hline $\begin{array}{l}\text { Ощущаемость } \\
\text { прошлого }\end{array}$ & $-0,244$ & 0,138 & $-0,365$ & $-1,768$ & 0,085 \\
\hline $\begin{array}{l}\text { Активность } \\
\text { настоящего }\end{array}$ & $-0,385$ & 0,140 & $-0,727$ & $-2,752$ & 0,009 \\
\hline $\begin{array}{l}\text { Структура } \\
\text { настоящего }\end{array}$ & 0,229 & 0,117 & 0,320 & 1,954 & 0,058 \\
\hline $\begin{array}{l}\text { Ощущаемость } \\
\text { настоящего }\end{array}$ & 0,424 & 0,156 & 0,760 & 2,716 & 0,010 \\
\hline $\begin{array}{l}\text { Эмоции } \\
\text { будущего }\end{array}$ & $-0,391$ & 0,142 & $-0,816$ & $-2,750$ & 0,009 \\
\hline $\begin{array}{l}\text { Величина } \\
\text { булущего }\end{array}$ & 0,315 & 0,131 & 0,664 & 2,407 & 0,021 \\
\hline $\begin{array}{l}\text { Ощущаемость } \\
\text { будущего }\end{array}$ & $-0,351$ & 0,116 & $-0,433$ & $-3,026$ & 0,004 \\
\hline
\end{tabular}


БРЕДУН Е. В., БАЛАНЁВ Д. Ю., ВАУЛИНА Т. А., КРАСНОРЯДЦЕВА О. М., ЩЕГЛОВА Э. А.

ТЕМПОРАЛЬНЫЕ ОСОБЕННОСТИ СТУДЕНТОВ КАК КОГНИТИВНЫЕ ДИАГНОСТИЧЕСКИЕ ХАРАКТЕРИСТИКИ...

РосСИйский психологИЧЕСКИй жУРнАл, 2020, Т. 17, № 1, 60-73. doi: 10.21702/rpj.2020.1.5

ПЕДАГОГИЧЕСКАЯ ПСИХОЛОГИЯ

Полученная прогностическая модель показывает, что респонденты, которые структурируют свое настоящее время с ориентацией на будущее время, как правило, могут быть более успешны в обучении (будут характеризоваться более высокой академической успеваемостью). В то время как студенты, которые в большей степени ориентированы на настоящее и будущее, представляют абстрактный образ, наполненный скорее эмоциями, нежели целями и действиями, окажутся менее успешными в обучении (будут иметь более низкую академическую успеваемость).

Поскольку оценка успешности в обучении включает в себя не только общий рейтинговый балл, но и стабильность учебных достижений, в данном исследовании по итогам результатов всех учебных сессий, в зависимости от стабильности/нестабильности учебных достижений, студенты были поделены на 7 групп: группа 1 - нестабильно по-разному; группа 2 - нестабильно успешные («5», «4» или неявка); группа 3 - стабильно неуспешные; группа 4 - стабильное снижение успешности; группа 5 - стабильно посредственно; группа 6 - стабильное повышение успешности; группа 7 - стабильно успешные.

Для исследования влияния когнитивных способностей, проявляющихся при решении задач на ментальное вращение, на стабильность академической успеваемости студентов, был проведен регрессионный анализ, при котором роль зависимой переменной (отклика) выполнял показатель стабильности, а в качестве предикторов выступали показатели скорости и точности, регистрируемые прибором при решении задач на ментальное вращение. В результате была получена регрессионная модель ( $(=0,000)$, характеризующая квадратичную зависимость стабильности академической успеваемости от точности выполнения задач на ментальное вращение (табл. 4 и рис. 1).

\footnotetext{
Таблица 4

Сводка Аля модеми и оценки параметров
}

Зависимая переменная: стабильность

Сводка $\triangle \wedge я$ модели

Оценки параметров

Урав-

нение
R-кваАрат
$\mathrm{F}$
СТ. Св. 1
Ст. Св. 2
Значи-
мость
Константа
b1
b2

Ква_pq-

тичная

0,143

10,976

2

132

0,000

5,062

$-2,688 \mathrm{E}-7$

$6,473 E-15$

Независимая переменная - это точность. 
БРЕДУН Е. В., БАЛАНЁв Д. Ю., ВАУЛИНА Т. А., КРАСНОРЯДЦЕВА О. М., ЩЕГЛОВА Э. А.

ТЕМПОРАЛЬНЫЕ ОСОБЕННОСТИ СТУДЕНТОВ КАК КОГНИТИВНЫЕ ДИАГНОСТИЧЕСКИЕ ХАРАКТЕРИСТИКИ...

РОССИЙСКИЙ ПСИХОЛОГИЧЕСКИЙ ЖУРНАЛ, 2020, Т. 17, № 1, 60-73. doi: 10.21702/rpj.2020.1.5

ПЕДАГОГИЧЕСКАЯ ПСИХОЛОГИЯ

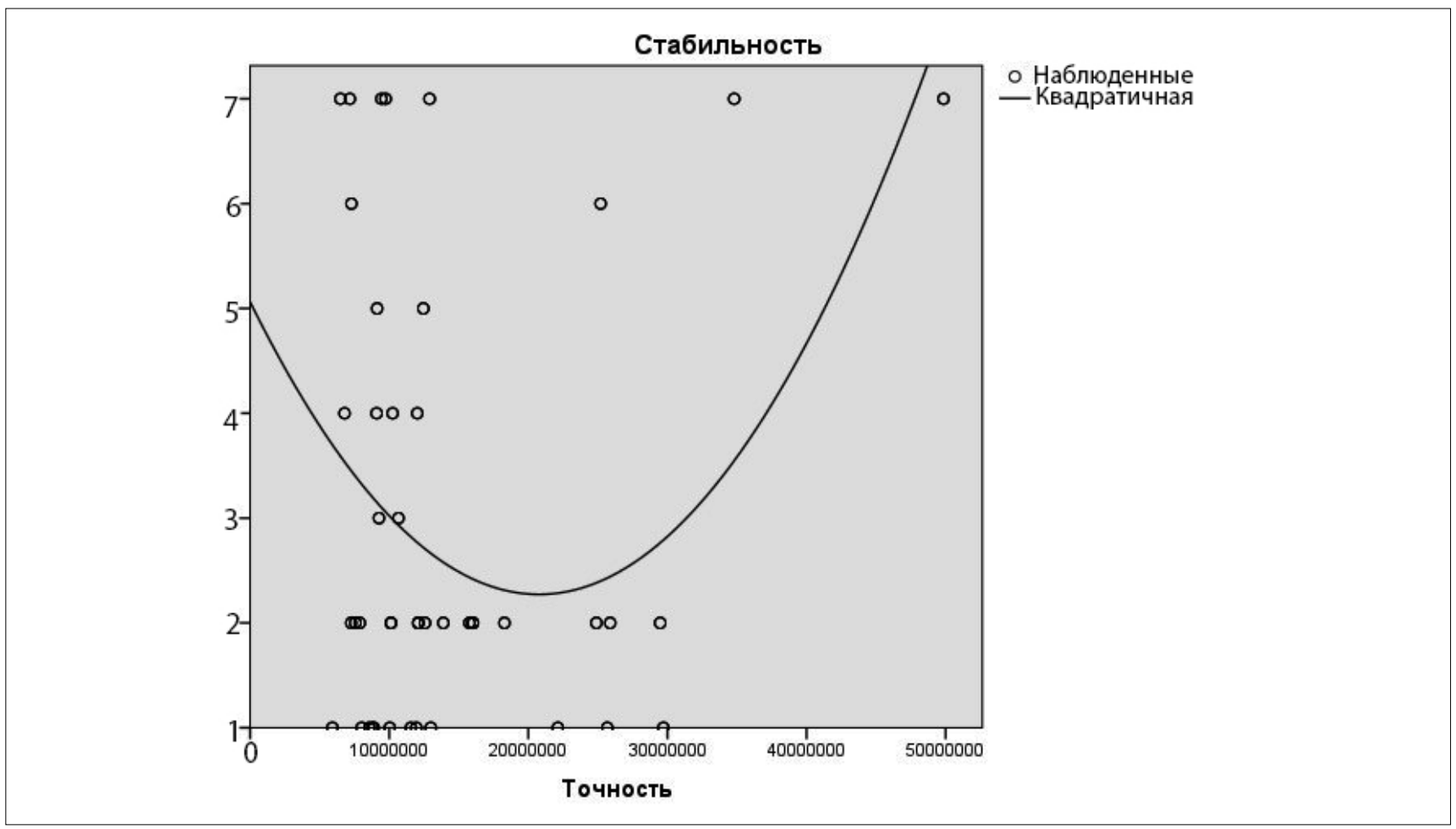

Рисунок 1. Регрессионная модель, характеризующая зависимость стабильности акалемической успеваемости от точности выполнения залач на ментальное вращение

На основании полученной регрессионной модели можно утверждать, что при низкой и высокой точности наблюдается более стабильная академическая успеваемость студентов, в то время как при средней точности выполнения заданий студенты демонстрируют нестабильность, разную успешность в сдаче экзаменов.

Детальный анализ результатов лабораторного эксперимента в выделенных группах студентов с различной стабильностью академической успеваемости позволяет говорить о наблюдаемых тенденциях влияния когнитивных особенностей на академическую успеваемость студентов и, в частности, на демонстрируемую ими стабильность в обучении. Результаты данного анализа, особенности выполнения заданий на ментальное вращение (скорости и точности), демонстрируемые студентами с различной стабильностью академической успеваемости, графически представлены на рисунках 2, 3, 4.

Полученные данные (рис. 4) показывают, что респонденты, отнесенные к группам стабильно снижающейся успеваемости, стабильно неуспешной и стабильно посредственной академической успеваемости, на выполнение когнитивных заданий на точность тратили значительно меньше времени по сравнению с другими респондентами. Следует также отметить, что студенты, обучающиеся стабильно на «отлично» и «хорошо» (стабильно успешные) наиболее долго выполняли предложенные задания на точность по сравнению с другими студентами.

Результаты решения студентами более сложных когнитивных задач на ментальное вращение имеют несколько иную картину (рис. 3). 
БРЕДУН Е. В., БАЛАНЁВ Д. Ю., ВАУЛИНА Т. А., КРАСНОРЯДЦЕВА О. М., ЩЕГЛОВА Э. А.

ТЕМПОРАЛЬНЫЕ ОСОБЕННОСТИ СТУДЕНТОВ КАК КОГНИТИВНЫЕ ДИАГНОСТИЧЕСКИЕ ХАРАКТЕРИСТИКИ...

РоссиЙский псИХологИчЕСКИй ЖУРнАл, 2020, Т. 17, № 1, 60-73. doi: 10.21702/rpj.2020.1.5

ПЕДАГОГИЧЕСКАЯ ПСИХОЛОГИЯ

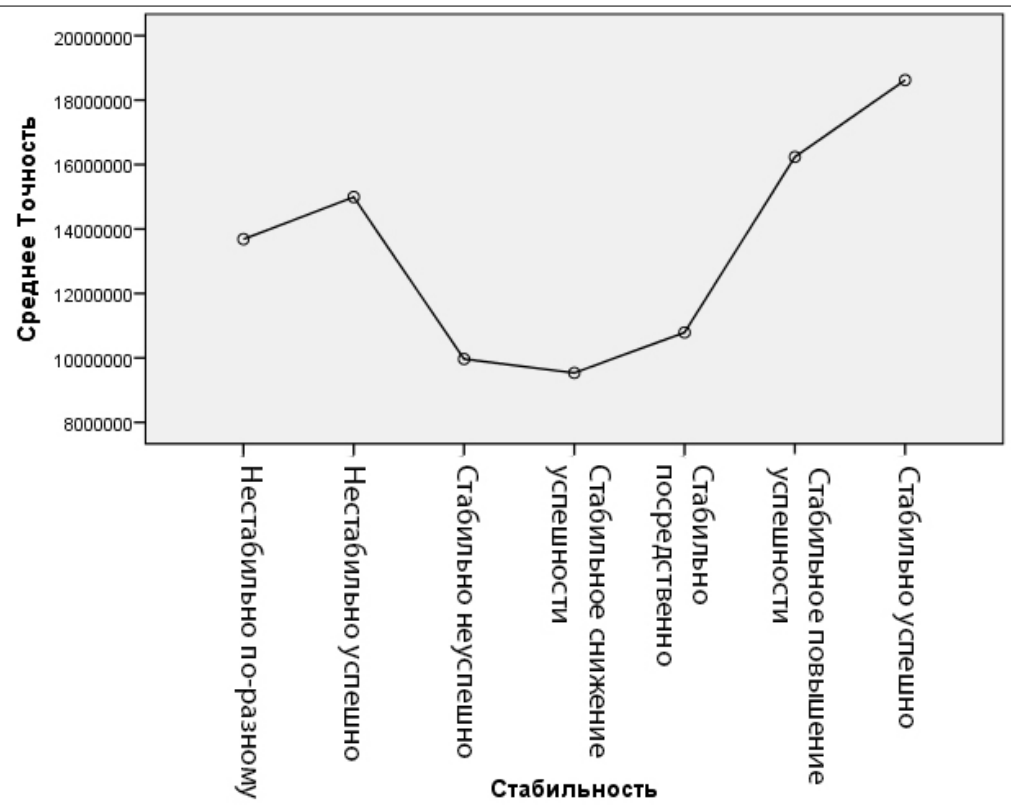

Рисунок 2. Результаты среАней скорости выполнения когнитивных залач на точность в группах стулентов с разной стабильностью акалемической успеваемости

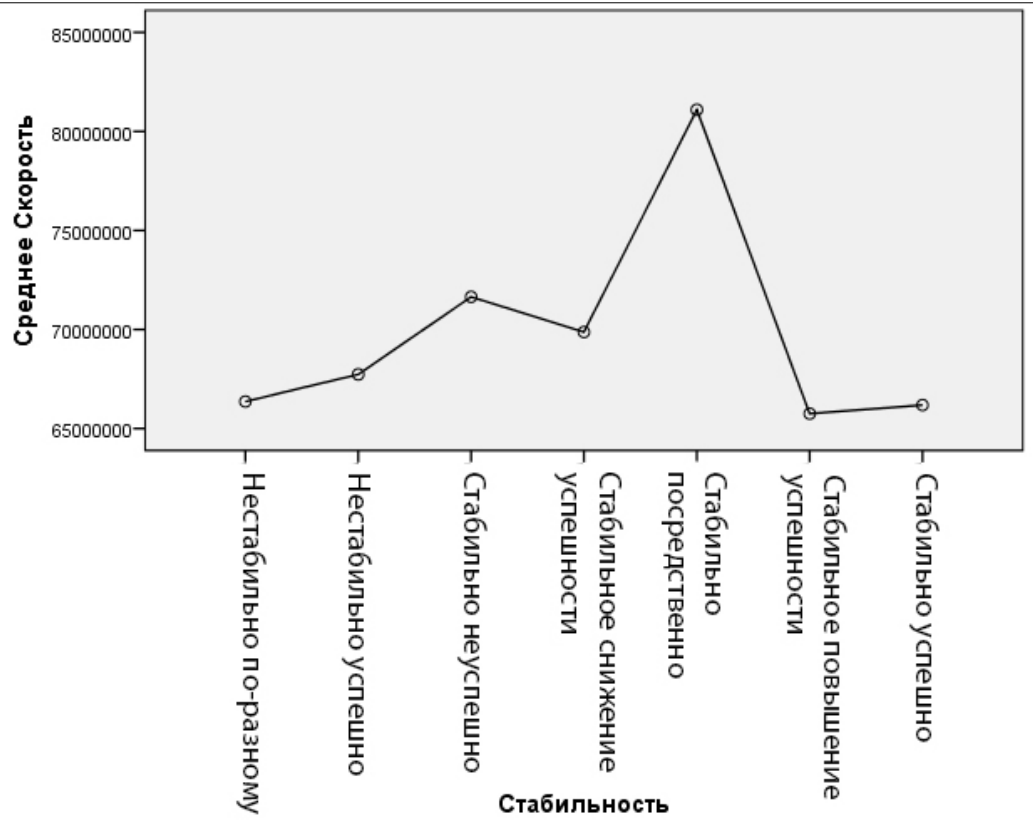

Рисунок 3. Результаты среАней скорости выполнения когнитивных залач ментального вращения в группах стулентов с разной стабильностью акалемической успеваемости 
БРЕДУН Е. В., БАЛАНЁВ Д. Ю., ВАУЛИНА Т. А., КРАСНОРЯДЦЕВА О. М., ЩЕГЛОВА Э. А.

ТЕМПОРАЛЬНЫЕ ОСОБЕННОСТИ СТУДЕНТОВ КАК КОГНИТИВНЫЕ ДИАГНОСТИЧЕСКИЕ ХАРАКТЕРИСТИКИ...

РОССИЙСКИЙ пСИХОЛОГИЧЕСКИЙ ЖУРнАл, 2020, Т. 17, № 1, 60-73. doi: 10.21702/rpj.2020.1.5

ПЕДАГОГИЧЕСКАЯ ПСИХОЛОГИЯ

Анализ полученных данных показывает, что студенты, которые демонстрируют стабильно посредственную успеваемость на протяжении всего периода обучения в вузе, на решение когнитивных задач ментального вращения тратили значительно больше времени по сравнению со студентами, отнесенными к другим группам (стабильно успешные, нестабильно успешные, нестабильно по-разному и со стабильным повышением успешности). При этом они (студенты со стабильно посредственной успеваемостью) допускают очень мало ошибок по сравнению с другими группами, за исключением студентов, которые демонстрируют снижение успеваемости (рис. 4). Респонденты, успеваемость которых со временем снижается, при решении когнитивных задач ментального вращения также допускали незначительное количество ошибок по сравнению со студентами других групп. Студенты, демонстрирующие нестабильность в обучении и получающие на экзаменах разные оценки (от «неудовлетворительно» до «отлично»), и студенты, которые сдают все экзамены или только на «отлично» (редко на «хорошо»), или не приходят на экзамен, если не уверены в своей подготовке, при решении когнитивных задач ментального вращения допускали наибольшее количество ошибок по сравнению с другими группами (рис. 4).

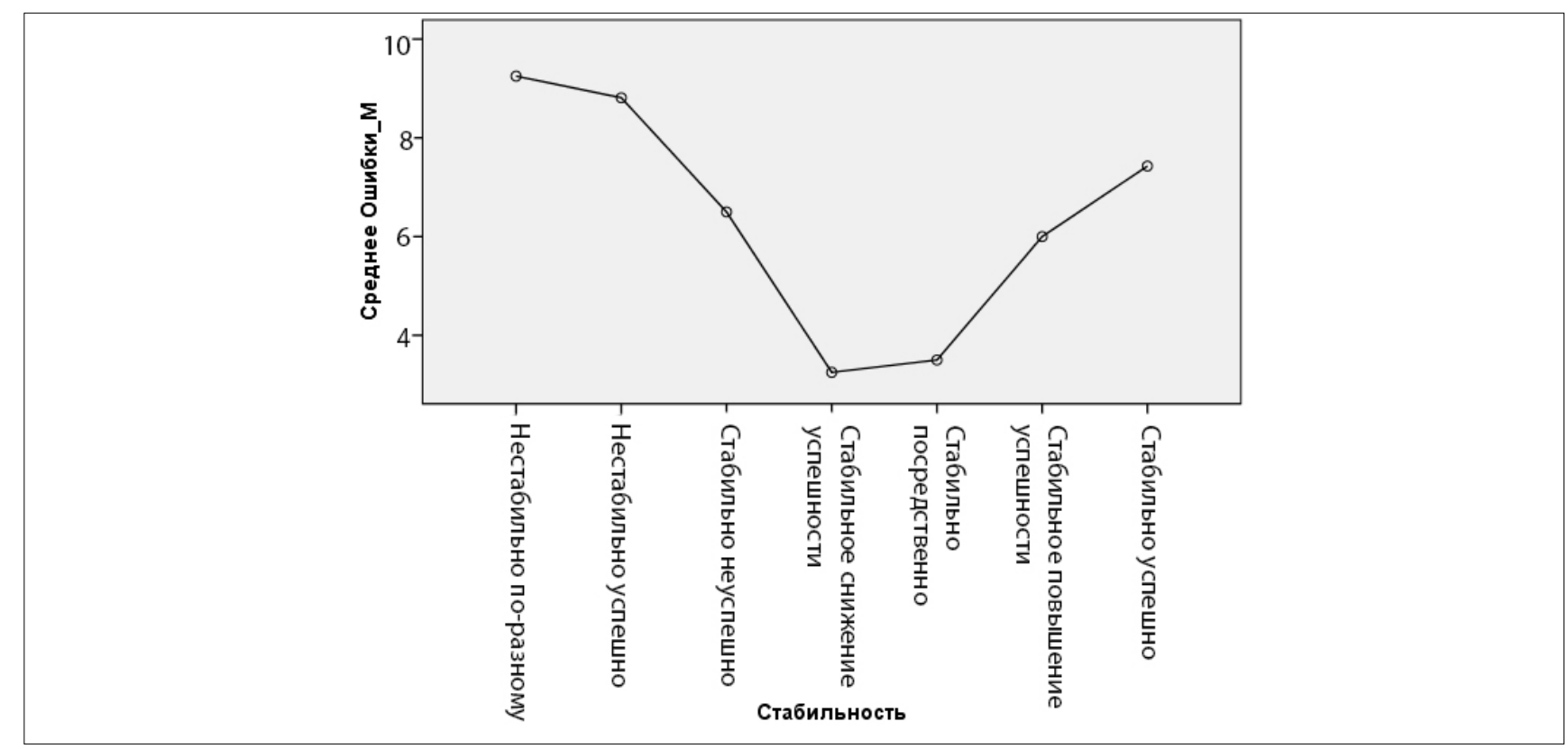

Рисунок 4. Результаты количества ошибок при выполнении когнитивных залач ментального вращения в группах студентов с разной стабильностью акалемической успеваемости

Таким образом, усложнение когнитивной задачи ментального вращения, в сравнении с когнитивной задачей на точность, продемонстрировало, что респондентам, отнесенным к группам низкой академической успешностью, понадобилось больше времени на выполнение заданий. А респондентам, отнесенным к группам с более высокой академической успешностью, наоборот, меньше времени требовалось на решение задач ментального вращения и больше времени, в сравнении с другими группами, на решение задач на точность. Кроме 
БРЕДУН Е. В., БАЛАНЁВ Д. Ю., ВАУЛИНА Т. А., КРАСНОРЯДЦЕВА О. М., ЩЕГЛОВА Э. А.

ТЕМПОРАЛЬНЫЕ ОСОБЕННОСТИ СТУДЕНТОВ КАК КОГНИТИВНЫЕ ДИАГНОСТИЧЕСКИЕ ХАРАКТЕРИСТИКИ...

РоссиЙскиЙ психологИЧЕСКИЙ жУРнАл, 2020, Т. 17, № 1, 60-73. doi: 10.21702/rpj.2020.1.5

ПЕДАГОГИЧЕСКАЯ ПСИХОЛОГИЯ

того, «нестабильно успешные» совершили наибольшее количество ошибок, в то время как наименее академически успешные и стабильно посредственно успешные респонденты лучше всего справились с задачами ментального вращения.

Важно отметить, что в обеих экспериментальных процедурах скорость предъявления задач зависела от самого респондента, соответственно, они выполняли задания в том ритме, который был для них наиболее удобен. Студенты, которые имеют низкую или посредственную академическую успеваемость, тратили столько времени на решение когнитивной задачи, сколько им было необходимо, анализируя каждую задачу в своем темпе. Это позволило им достигнуть больших успехов, в сравнении с другими респондентами. В свою очередь, академически успешные студенты больше ориентировались не на результат, а на скорость, на возможность быстрее закончить задание. Возможно, они проанализировали задачи на первых заданиях, и решение последующих представляло собой интегративный процесс, когда каждый последующий стимул сравнивается с предъявленными ранее. И поэтому участник уделял мало времени на решение каждой задачи, опираясь на полученный опыт, что привело к большому количеству ошибок, т. к. все стимулы в данном эксперименте имели разную когнитивную нагрузку.

\section{Обсуждение результатов}

Использование экспериментальных методик позволило получить фактологический исследовательский материал, наглядно иллюстрирующий индивидуальное темпоральное своеобразие самого процесса организации студентом когнитивного пространства в ситуации реального решения пространственных задач. Выявлены тенденции влияния таких темпоральных особенностей, как скорость и точность решения когнитивных задач, на академическую стабильность студентов. Это дает основания для вывода о том, что темпоральные особенности студентов могут рассматриваться как прогностические когнитивные диагностические характеристики академической успешности.

Экспериментально доказано, что обладая разными темпоральными характеристиками, студенты не всегда в состоянии соответствовать временному пространству когнитивной среды и тем требованиям, которые она предъявляет. Скорость переработки информации, временные затраты на изучение материала или решение задачи могут выступать одним из определяющих факторов академической успешности. В этой связи можно предположить, что если студент будет затрачивать на изучение материала столько времени, сколько ему требуется, то он может продемонстрировать более высокий уровень успешности. Таким образом, содействие развитию у человека способности к самостоятельному структурированию когнитивной деятельности неэффективно без учета временных характеристик.

Особого внимания заслуживает, с нашей точки зрения, тот факт, что у студентов с доминирующей временной ориентацией на настоящее и отличающихся тем, что они постоянно ищут новые стимулы и ощущения в актуальном времени, есть достаточно выраженные дефициты в выборе образовательных стратегий на основе более долгосрочных и четких целей на будущее. Представляется, что направленность основных образовательных программ профессиональной подготовки студентов на развитие у них готовности и способности к постановке и решению стратегических задач своего жизнеосуществления (в том числе и профессионального) повысит учебную самоорганизацию студента и в настоящем времени.

Констатация темпоральных различий у субъектов образовательного процесса может рассматриваться как еще одно основание необходимости разнообразия вариантов образовательных 
БРЕДУН Е. В., БАЛАНЁВ Д. Ю., ВАУЛИНА Т. А., КРАСНОРЯДЦЕВА О. М., ЩЕГЛОВА Э. А.

ТЕМПОРАЛЬНЫЕ ОСОБЕННОСТИ СТУДЕНТОВ КАК КОГНИТИВНЫЕ ДИАГНОСТИЧЕСКИЕ ХАРАКТЕРИСТИКИ...

РосСИЙСКИЙ пСИХОЛОГИЧЕСКИЙ ЖУРнАл, 2020, Т. 17, № 1, 60-73. doi: 10.21702/rpj.2020.1.5

ПЕДАГОГИЧЕСКАЯ ПСИХОЛОГИЯ

траекторий. Каждый вид образовательных технологий предполагает определенную темпоральность, не всегда учитывающую разнообразие доминирующих модальностей субъективного восприятия времени обучающихся. В этой связи важным аспектом в персонализации обучения является то, что студент сам должен понимать, какие временные, когнитивные и иные особенности переработки информации он имеет, чтобы самостоятельно организовывать свою образовательную среду. Понимание когнитивных особенностей позволяет выявить индивидуальные различия переработки информации, а также организовать образовательное сопровождение прогнозирования индивидуальной траектории образовательного пути студента. Тем более что количество неуспешных студентов, которые проявляют низкую способность к саморегуляции в образовательной среде, продолжает оставаться достаточно высоким.

Одним из наиболее перспективных направлений практического применения полученных исследовательских результатов представляется адаптивный подход в образовании, активно развиваемый в условиях нарастающей цифровизации современного образования (Borba et al., 2017; Gibson, 2017; Nguyen, Hsieh, \& Allen, 2006; Zitter, De Bruijn, Simons, \& Cate, 2011; Павлов, 2017). Адаптивное образование представляется как инструмент, способный повысить качество образовательного опыта посредством его персонализации. В отличие от традиционных систем обучения, адаптивное образование позволит создать модель, определяющую индивидуальные различия каждого обучающегося (Nakic, Granic, \& Glavinic, 2015; Кочеткова и Кытманов, 2016; Токтарова, 2017; Шершнева, Вайнштейн и Кочеткова, 2018). Расширение индивидуализированных данных о студенте, сгенерированных методами аналитики психологических, темпоральных, когнитивных и иных данных, позволит переориентировать образовательный процесс на реальную индивидуализацию и осуществлять коррекцию индивидуальных образовательных траекторий студентов с учетом показателей динамики когнитивных характеристик.

\section{Благодарности}

Результаты были получены в рамках выполнения государственного задания Минобрнауки России, проект № 0721-2020-0040.

\section{Литература}

Болотова, А. К. (2006). Психология организации времени: Учебное пособие для студентов вузов. Москва: Аспект Пресс.

Бредун, Е. В., Краснорядцева, О. М. и Щеглова, Э. А. (2018). Типологические особенности субъективного восприятия времени в контексте хронотопической жизни человека. Сибирский психологический журнал, 68, 32-45.

Вассерман, Л. И., Трифонова, Е. А. и Червинская, К. Р. (2009). Семантический дифференциал времени: экспертная психодиагностическая система в медицинской психологии. СанктПетербург: СПбНИПНИ им. В. М. Бехтерева.

Гордеева, Н. Д. (1995). Экспериментальная психология исполнительного действия. Москва: Тривола.

Горобец, Т. Н. (2011). Индивидуальное восприятие ритмов и циклов времени в контексте их социальной обусловленности. Мир психологии, 3(67), 160-168.

Горькая, Ж. В. (2014). Социокультурный анализ психологии восприятия времени. Вестник Самарского государственного университета, 9, 245-250. 
БРЕДУН Е. В., БАЛАНЁВ Д. Ю., ВАУЛИНА Т. А., КРАСНОРЯДЦЕВА О. М., ЩЕГЛОВА Э. А.

ТЕМПОРАЛЬНЫЕ ОСОБЕННОСТИ СТУДЕНТОВ КАК КОГНИТИВНЫЕ ДИАГНОСТИЧЕСКИЕ ХАРАКТЕРИСТИКИ...

РосСИйскиЙ психологИЧЕСКИй жУРнАл, 2020, Т. 17, № 1, 60-73. doi: 10.21702/rpj.2020.1.5

ПЕДАГОГИЧЕСКАЯ ПСИХОЛОГИЯ

Зимбардо, Ф. и Бойд, Дж. (2010). Парадокс времени. Новая психология времени, которая улучшит вашу жизнь. Санкт-Петербург: Речь.

Клочко, В. Е., Краснорядцева, О. М. и Баланев, Д. Ю. (2016). Приемы и методы психологчческой реконструкции жизненного мира человека: постнеклассический ракурс. Томск: Изд-во ТГУ.

Кочеткова, Т. О. и Кытманов, А. А. (2016). Адаптационный курс математики в университете назад в будущее. Вестник Красноярского государственного педагогического университета им. В. П. Астафьева, 2(36), 60-63.

Павлов, А. Д. (2017). Анализ интеллектуальных механизмов и интеграция адаптивных методов обучения в систему MathBridge. Образовательные технологии и общество, 20(4), 344-355.

Токтарова, В. И. (2017). Адаптивная система математической подготовки студентов вуза: учет стилевых типологий обучающихся. Вестник Челябинского государственного педагогического университета, 6, 108-116.

Хмелевская, С. А. (2012). Темпомиры форм постижения бытия. Социально-политические науки, 4, 105-108.

Шершнева, В. А., Вайнштейн, Ю. В. и Кочеткова, Т. О. (2018). Адаптивная система обучения в электронной среде. Программные системы: теория и приложения, 9(4), 159-177.

Arstila, V., \& Lloyd, D. (2014). Subjective Time. The Philosophy, Psychology, and Neuroscience of Temporality. Cambridge, Massachusetts; London, England: The MIT Press.

Borba, M. C., Askar, P., Engelbrecht, J., Gadanidis, G., Llinares, S., \& Aguilar, M. S. (2017). Digital technology in mathematics education: Research over the last decade. In G. Kaiser (Ed.), Proceedings of the 13th International Congress on Mathematical Education. ICME-13 Monographs (pp. 221-233). Springer, Cham. doi: 10.1007/978-3-319-62597-3 14

Cooper, L. A., \& Shepard, R. N. (1973). Chronometric studies of the rotation of mental images. In W. G. Chase (Ed.), Visual information processing (pp. 75-176). New York: Academic Press.

Droit-Volet, S., Wearden, J. H., \& Zélanti, P. S. (2015). Cognitive abilities required in time judgment depending on the temporal tasks used: A comparison of children and adults. Quarterly Journal of Experimental Psychology, 68(11), 2216-2242. doi: 10.1080/17470218.2015.1012087

Frank, L. K. (1939). Time perspectives. Journal of Social Philosophy, 4, 293-312.

Gibson, D. (2017). Big data in higher education: Research methods and analytics supporting the learning journey. Technology, Knowledge and Learning, 22, 237-241. doi: 10.1007/s10758-017-9331-2

Grondin, S. (2010). Timing and time perception: A review of recent behavioral and neuroscience findings and theoretical directions. Attention, Perception, \& Psychophysics, 72(3), 561-582. doi: 10.3758/APP.72.3.561

Matthews, W. J., \& Meck, W. H. (2016). Temporal cognition: Connecting subjective time to perception, attention, and memory. Psychological Bulletin, 142(8), 865-907. doi: 10.1037/bul0000045

Nakic, J., Granic, A., \& Glavinic, V. (2015). Anatomy of student models in adaptive learning systems: A systematic literature review of individual differences from 2001 to 2013. Journal of Educational Computing Research, 51(4), 459-489. doi: 10.2190/EC.51.4.e

Nguyen, D. M., Hsieh, Y. C., \& Allen, G. D. (2006). The impact of web based assessment and practice on students' mathematics learning attitudes. Journal of Computers in Mathematics and Science Teaching, 25(3), 251-279.

Shepard, R. N., \& Metzler, J. (1971). Mental rotation of three-dimensional objects. Science, 171(3972), 701-703. doi: $10.1126 /$ science.171.3972.701 
Thomas, C., Didierjean, A., Maquestiaux, F., \& Goujon, A. (2018). On the limits of statistical learning: Intertrial contextual cueing is confined to temporally close contingencies. Attention, Perception, \& Psychophysics, 80, 1420-1435. doi: 10.3758/s13414-018-1519-6

van Heerden, A. (2016). The restructuring of temporality during art making. South African Journal of Art History, 31(2), 187-204.

Wearden, J. H. (2003). Applying the scalar timing model to human time psychology: Progress and challenges. In H. Helfrich (Ed.), Time and mind II: Information-processing perspectives (pp. 21-39). Gottingen: Hogrefe \& Huber.

Wittmann, M., Dinich, J., Merrow, M. \& Roenneberg, T. (2006). Social jetlag: Misalignment of biological and social time. Chronobiology International, 23(1-2), 497-509. doi: 10.1080/07420520500545979

Zimbardo, P. G., \& Boyd, J. N. (1999). Putting time in perspective: A valid, reliable individual-difference metric. Journal of Personality and Social Psychology, 77(6), 1271-1288. doi: 10.1037/0022-3514.77.6.1271

Zitter, I., De Bruijn, E., Simons, P. R. J., \& Cate, Th. J. T. (2011). Adding a design perspective to study learning environments in higher professional education. Higher Education, 61, 371-386. doi: $10.1007 /$ s10734-010-9336-4

\section{Конфликт интересов отсутствует}

